\title{
Exposure-response analysis of allergy and respiratory symptoms in endotoxin- exposed adults
}

\author{
L.A.M. Smit, D. Heederik, G. Doekes, C. Blom, I. van Zweden and I.M. Wouters
}

ABSTRACT: The objective of the present study was to investigate exposure-response relationships between current endotoxin exposure and allergic and respiratory symptoms in adults, taking into account farming exposures during childhood.

A cross-sectional study was conducted among 877 Dutch farmers and agricultural industry workers in 2006. Based on 249 full-shift personal airborne endotoxin samples, a job-exposure matrix was constructed to assign endotoxin exposure levels to all participants. Associations between endotoxin exposure and questionnaire data on symptoms were studied by multiple logistic regression.

Adjusted odds ratios (OR) for an interquartile range increase in endotoxin level were elevated for respiratory symptoms such as wheezing (OR 1.41 (95\% confidence interval 1.16-1.72)), wheezing with shortness of breath $(1.50(1.18-1.90))$ and daily cough (1.29 (1.03-1.62)). In contrast, endotoxin was strongly associated with a decreased prevalence of hay fever $(0.62)(0.49$ 0.78)). Workers who had grown up on a farm had a lower prevalence of hay fever, but no evidence was found of effect modification by farm childhood.

In conclusion, occupational endotoxin exposure in adulthood is associated with an increased risk of asthma-like symptoms but a reduced prevalence of hay fever.

KEYWORDS: Allergy, endotoxin exposure, epidemiology, farming, occupational exposure, respiratory symptoms

$\mathbf{N}$ umerous studies have shown a reduced prevalence of atopic disease in children and adults who lived on a farm during childhood, and this observation has been attributed to high microbial exposures in farm children [1-8]. Indeed, several studies have reported protective effects of increased domestic endotoxin exposure on the development of atopy and (atopic) asthma in children not only from farming, but also from urban environments [9-11]. Although it has been argued that especially microbial exposure in early childhood contributes to the reduction of allergic sensitisation [1, 5], there are studies suggesting that exposure during adulthood continues to protect against atopy. GEHRING et al. [12] found an association between elevated house-dust endotoxin levels and a decreased prevalence of allergic sensitisation in adults. In addition, two studies in farmers found inverse relationships between airborne endotoxin exposure and atopic asthma [13] and atopy [14]. A protective effect of exposure throughout life has also been suggested by studies that used current contact with livestock as a representative measure for high microbial exposure in adulthood, and found the lowest prevalence of atopy or hay fever in subjects with both a farm childhood and current contact with farm animals $[5,7,8]$.

Paradoxically, although microbial agents may protect against atopic disease, house-dust endotoxin has also been associated with asthma, asthma severity and nonatopic wheeze [10, 1517]. Moreover, a large number of epidemiological studies in occupational environments have consistently shown exposure-response relationships between exposure to endotoxin and other microbial agents such as fungal spores, and nonatopic asthma, airway obstruction, accelerated lung function decline, bronchial hyperresponsiveness and organic dust toxic syndrome [13, 14, 18-20]. These two aspects of microbial exposure were well illustrated in studies among farmers, demonstrating an inverse association between airborne endotoxin exposure and atopy or atopic asthma, but also an increased risk of airway responsiveness, a lower lung function and
AFFILIATION

Institute for Risk Assessment

Sciences, Division of Environmental Epidemiology, Utrecht University,

Utrecht, The Netherlands.

CORRESPONDENCE

L.A.M. Smit

Institute for Risk Assessment

Sciences

Division of Environmental

Epidemiology

PO Box 80178

3508 TD Utrecht

The Netherlands

Fax: 31302539499

E-mail: L.Smit@uu.nl

Received:

July 182007

Accepted after revision:

January 192008

SUPPORT STATEMENT

I.M. Wouters and L.A.M. Smit were supported by the Netherlands Asthma Foundation (grant no. 3.2.03.70).

STATEMENT OF INTEREST None declared.

European Respiratory Journal Print ISSN 0903-1936 Online ISSN 1399-3003 
nonatopic asthma $[13,14]$. However, these effects of current endotoxin exposure might be partly due to childhood exposure, which has not been taken into account.

Therefore, the objective of the present cross-sectional study was to investigate the role of airborne endotoxin exposure in adulthood and farming exposures during childhood on the occurrence of allergic and respiratory symptoms in adults exposed to a wide range of work-related endotoxin levels.

\section{METHODS}

\section{Study population}

The study population consisted of workers involved in processing and trade of agricultural products who were recruited in collaboration with their product boards, and farmers who were recruited through the records of the inspection body for organic production in the Netherlands (Skal, Zwolle, the Netherlands). The study was carried out between February and December 2006.

Questionnaires were sent to all employees of 23 participating companies, a representative sample of companies in four agricultural sectors (onion trade, flower bulb trade, animal feed industry and vegetable seed industry), 2 weeks before the companies were visited for exposure measurements. In total, 376 completed questionnaires were received, a response rate of $90 \%$. Farmers were recruited by sending questionnaires to 748 farm owners, and everyone aged $>18$ yrs and working on the farm was invited to complete a questionnaire. Up to two postal reminders were sent to nonresponders. Of the 748 farm owners approached initially, 59 had left farming and were excluded from the study. In total, 525 completed questionnaires were received from 418 farms, thus the farm owners' response rate was $61 \%$. The majority of farm owners $(78 \%)$ had shifted from conventional to organic farming, on average $7.1 \mathrm{yrs}$ ago, whereas $22 \%$ had never practiced conventional farming. Overall, 23 subjects aged $<18$ or $>65$ yrs and one subject with missing data on farm childhood were excluded from the study. Altogether, data from 877 questionnaires were used for statistical analysis.

Of the 525 farmers who completed the questionnaire, 340 (65\%) indicated that they would not object to being contacted for exposure measurements. A sample of 122 farmers was approached by telephone on the basis of distance from the present authors' laboratory (Utrecht, the Netherlands), and 82 farmers were able to participate in personal exposure measurements on one of the proposed dates. During visits to the agricultural companies, 116 workers across all different worksites were asked to participate in exposure measurements; all invited workers agreed to participate. Single measurements were obtained from 65 workers, and from 51 workers two samples were obtained on 2 consecutive days, resulting in a total of 249 full-shift inhalable dust and endotoxin measurements. Farms and agricultural companies were visited on random days and, therefore, measurements reflected average exposures rather than exposures related to specific tasks.

\section{Questionnaire}

Questions about respiratory symptoms were adopted from the Dutch version of the European Community Respiratory Health
Survey (ECRHS) questionnaire [21, 22]. Current wheezing was defined as wheezing at any time in the last 12 months. Doctordiagnosed asthma was defined as ever having had asthma that was confirmed by a doctor, and was stratified by time of onset (before or after $18 \mathrm{yrs}$ of age). Questions about personal characteristics, allergy, smoking habits, farm childhood and farm characteristics were obtained from an earlier questionnaire survey among farmers [7]. A farm childhood was defined as a positive answer to the question "Did you grow up on a farm?" A positive response to the question "Have you ever had any allergies?" was followed by a list of possible allergens (house dust, food, animals, pollen) and symptoms (sneezing or runny nose, dyspnoea, itchy skin, or itchy or watery eyes). Hay fever was defined as self-reported pollen allergy experienced as itchy or watery eyes or sneezing [7]. Job title, workplace and tasks of employees of agricultural companies were assessed by questions developed in collaboration with the respective product boards.

\section{Endotoxin exposure assessment}

Full-shift inhalable dust samples were collected using Gilian GilAir portable pumps (Gilian, West Caldwell, NJ, USA) at a flow rate of $3.5 \mathrm{~L} \cdot \mathrm{min}^{-1}$ using Gesamt Staub Probenehmer (GSP) sampling heads and 37-mm glass-fibre filters (Whatman GF/A, Maidstone, UK). Filters were extracted in pyrogen-free water with $0.05 \%$ Tween 20 [23]. Supernatants were analysed by the quantitative kinetic chromogenic Limulus amebocyte lysate assay (lysate lot no. EL004V, standard lot no. 4L3560; Cambrex, Verviers, Belgium) [23]. Endotoxin levels were above the limit of detection in all samples. Results were expressed as endotoxin units $(\mathrm{EU}) \cdot \mathrm{m}^{-3}(18 \mathrm{EU}=1 \mathrm{ng})$.

\section{Data analysis}

Data analysis was performed on natural log-transformed endotoxin concentrations. Mixed effects models that assume correlation between repeated exposure measurements in the same worker were applied for each sector separately, including worker as random effect and job title as fixed effect, to calculate geometric mean (GM) exposure levels for different job titles [24]. The resulting job-exposure matrix was combined with the job title of all participating subjects to assign endotoxin exposure. Exposure measurements were available for each of the 30 combinations of sector or farm type and job title. Modelled endotoxin exposure showed good correlation with measured exposure $(\mathrm{r}=0.76, \mathrm{p}<0.001)$ in the subjects with measurement data available. The shape of the relationship between modelled endotoxin exposure and health outcomes was studied by means of generalised additive modelling (smoothing), as described previously [14]. If the smoothed relationship was not significantly different from a linear fit, multiple linear logistic regression analyses were applied to calculate odds ratios (ORs) for an interquartile range increase in endotoxin exposure. ORs for subjects at the 75th percentile of endotoxin exposure versus subjects at the 25th percentile and $95 \%$ confidence intervals (CI) were calculated by exponentiating regression coefficients and their CI after multiplying by the interquartile range of in-transformed endotoxin exposure $(1.45$ corresponding to a factor $\exp ^{1.45}=4.3$ for non-transformed values). ORs were adjusted for age, sex, smoking habits and farm childhood. To investigate effect modification by farm childhood or self-reported allergy, interactions between farm 
childhood and endotoxin exposure, and allergy and endotoxin exposure were explored and tested.

\section{RESULTS}

Table 1 shows characteristics of the study population, stratified by farm childhood. Workers who had grown up on a farm were more often working in primary agricultural production, male and older, and were less often current smokers than workers without a farm childhood $(p<0.05$; Chi-squared test and unpaired t-test). The average endotoxin exposure levels were, however, practically identical $\left(\mathrm{GM} 265 \mathrm{EU} \cdot \mathrm{m}^{-3}\right)$, and a wide range of exposure levels was found in both subgroups.

The exposure data underlying the job-exposure matrix used to assign endotoxin exposure levels to all subjects is presented in table 2. Exposure levels were comparable with those in recent studies in agricultural industries [25, 26]. Highest endotoxin levels were found among onion workers and animal feed unloaders $\left(\mathrm{GM} \sim 10,000 \mathrm{EU} \cdot \mathrm{m}^{-3}\right)$. Levels among crop farmers $\left(\mathrm{GM} 63 \mathrm{EU} \cdot \mathrm{m}^{-3}\right)$ were lower than levels in dairy farmers or pig farmers (GM $220 \mathrm{EU} \cdot \mathrm{m}^{-3}$ and 3,400 $\mathrm{EU} \cdot \mathrm{m}^{-3}$, respectively).

Hay fever prevalence declined with increasing endotoxin exposure, but a positive relationship between endotoxin and wheezing was found (fig. 1). The slope of exposure-response relationships was similar in workers who had grown up on a farm and those without a farm childhood, although the prevalence of hay fever was lower in the former group (fig. 1).

Comparison of smoothed and parametric models showed that associations could be described satisfactorily with parametric logistic regression models, and ORs were, therefore, calculated for an interquartile range increase in endotoxin exposure with

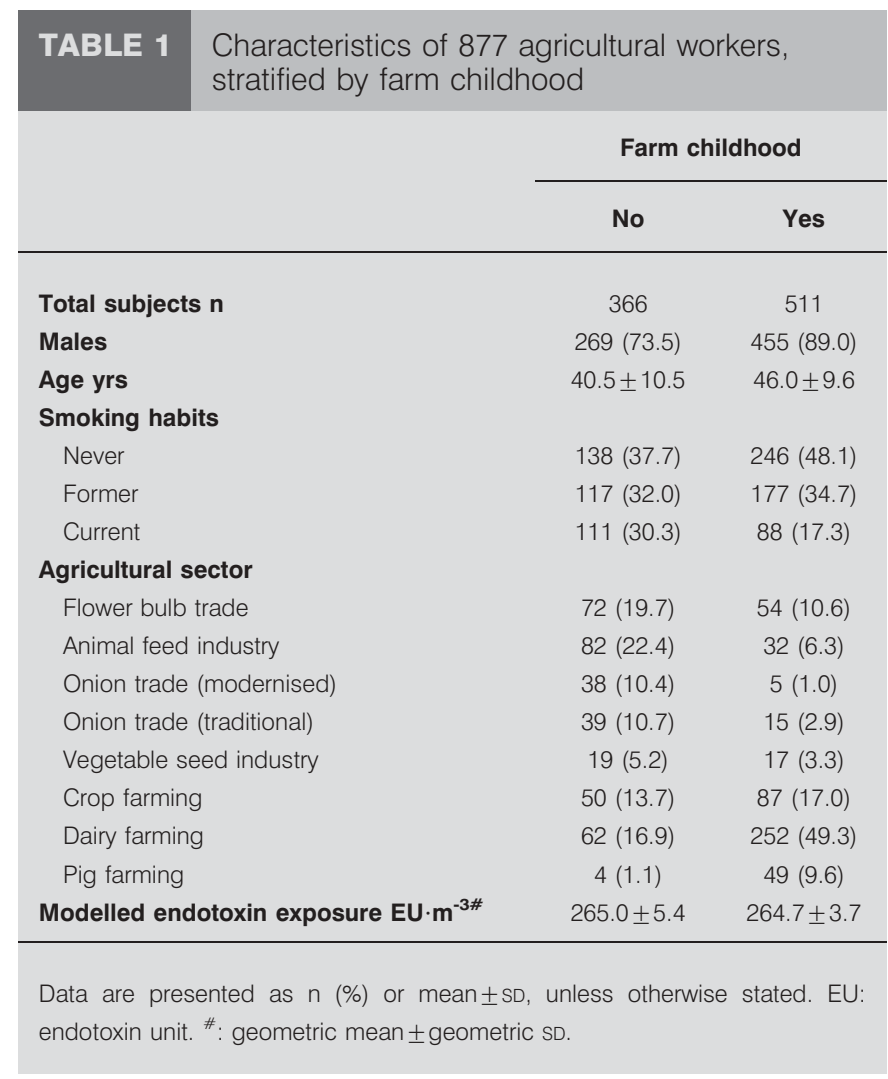

multiple logistic regression models. Increased endotoxin exposure was significantly associated with cough symptoms, shortness of breath and wheezing, but inversely related to allergy and hay fever (table 3). The prevalence of doctordiagnosed asthma was low (both childhood and adult-onset asthma) and was not related to endotoxin level. Associations between endotoxin exposure and health outcomes were not modified by farm childhood, i.e. no significant interaction was observed for any of the symptoms $(p>0.1)$. Subjects with a farm childhood reported significantly less often that they had woken up due to cough than workers without a farm childhood (OR 0.64 (95\% confidence interval (CI) 0.42-0.98)). A farm childhood was also associated with less reported hay fever, although this difference was not statistically significant (0.65 (0.41-1.03)). Female workers reported more cough (1.91 (1.06-3.46)) and waking up due to cough (2.46 (1.54-3.91)) compared with male workers. Adjustment for sex, age, smoking habits and farm childhood, however, did not meaningfully change ORs for the relationships between current endotoxin exposure and health outcomes.

To disentangle associations between allergy, respiratory symptoms and endotoxin, the present authors investigated whether self-reported allergy modified associations between endotoxin exposure and respiratory symptoms, such as wheezing. As expected, the prevalence of all respiratory symptoms was higher in subjects who reported allergy (table 4). However, ORs for the relationship between endotoxin exposure and respiratory symptoms were essentially equal in both strata, and there was no significant interaction $(p>0.2)$. Self-reported allergy was strongly associated with respiratory symptoms ( $\mathrm{p}$-values $<0.001-0.09$ ), and controlling for confounding by allergy resulted in higher ORs for respiratory symptoms (model 2, table 4). Thus, adverse effects of endotoxin might be somewhat underestimated due to confounding by atopy.

In a subgroup of 429 workers, self-reported allergy was validated against specific serum immunoglobulin (Ig)E levels, which were measured by means of enzyme immunoassays, and atopy was defined as serum $\operatorname{IgE}$ to one or more of the common allergens: grass pollen, house-dust mite, cat and dog [27]. Strong associations were observed between allergy and atopy (OR 8.5, 95\% CI (5.0-14.5)), and between hay fever and IgE to grass pollen (18.2 (9.1-36.6)).

In addition, the present authors investigated whether the associations between endotoxin and health effects differed between the various agricultural sectors included in the study. Endotoxin was dichotomised using the median exposure level for each sector as a cut-off. Highly consistent results were found across the different sectors, although statistical significance was only reached within the relatively large group of farmers (table 5). Endotoxin exposure above the median level led in all groups to an approximately two-fold higher risk of wheezing, whereas the risk of hay fever was two to five times lower. Only in the small group of vegetable seed workers was no association between endotoxin exposure and hay fever observed. Although similar ORs were found, the prevalence of symptoms was not equal in groups with different exposure levels, which explains the monotonous dose-response curves presented in figure 1. 
TABLE 2 Measured endotoxin exposure levels in agricultural workers, by job title

\begin{tabular}{|c|c|c|c|}
\hline Sector and job title & $\begin{array}{c}\text { Participants in questionnaire } \\
\text { study }\end{array}$ & $\begin{array}{l}\text { Personal endotoxin } \\
\text { measurements }\end{array}$ & $\begin{array}{c}\text { Endotoxin exposure } \\
\qquad \mathrm{EU} \cdot \mathrm{m}^{-3}\end{array}$ \\
\hline Office worker & 40 & 3 & $15 \pm 1.1$ \\
\hline Fork-lift truck operator & 10 & 2 & $86 \pm 1.3$ \\
\hline Technician & 4 & 2 & $93 \pm 1.5$ \\
\hline Operator & 55 & 14 & $690 \pm 2.9$ \\
\hline \multicolumn{4}{|l|}{ Animal feed industry } \\
\hline Office worker & 9 & 6 & $35 \pm 2.1$ \\
\hline Lab worker & 3 & 4 & $59 \pm 2.1$ \\
\hline Control room worker & 31 & 19 & $250 \pm 4.1$ \\
\hline Cleaner & 2 & 3 & $1000 \pm 4.4$ \\
\hline Unloader & 5 & 5 & $9500 \pm 2.8$ \\
\hline \multicolumn{4}{|l|}{ Onion trade (modernised) } \\
\hline Office worker & 8 & 3 & $380 \pm 3.7$ \\
\hline Packer & 5 & 1 & 630 \\
\hline Fork-lift truck operator & 13 & 2 & $1100 \pm 2.4$ \\
\hline Operator & 19 & 6 & $1300 \pm 3.3$ \\
\hline \multicolumn{4}{|l|}{ Onion trade (traditional) } \\
\hline Technician & 3 & 2 & $800 \pm 3.5$ \\
\hline Fork-lift truck operator & 13 & 6 & $4100 \pm 3.7$ \\
\hline Packer & 4 & 4 & $5300 \pm 1.4$ \\
\hline Operator & 32 & 15 & $10000 \pm 1.6$ \\
\hline Livestock farmer, mainly dairy & 314 & 46 & $220 \pm 4.6$ \\
\hline Pig farmer & 53 & 6 & $3400 \pm 6.9$ \\
\hline
\end{tabular}

Data are presented as $n$ or geometric mean \pm geometric SD. EU: endotoxin unit.

\section{DISCUSSION}

The present study found that current occupational exposure to endotoxin was associated with a reduced prevalence of hay fever in adults, regardless of childhood exposure. However, in the same population, a positive dose-dependent association between endotoxin exposure and adverse respiratory effects, such as wheezing, shortness of breath and cough, was found. To the present authors' knowledge, this is the first study showing an inverse association between measured airborne endotoxin exposure and allergy in adults, while taking farming exposures during childhood into account.

The pro-inflammatory properties of endotoxin can explain the increased risk of airway symptoms such as wheezing and cough. Conversely, endotoxin is thought to reduce the risk of allergic sensitisation by inducing a shift from allergic T-helper cell (Th) type 2 responses to Th1-dominated responses, through stimulation of the innate immune system and regulatory T-cells [28]. The results of the present study suggest that inhaled endotoxin may exert such immune-modulating effects beyond childhood, and similar conclusions were previously derived from a longitudinal study showing that young adult dairy farmers may lose allergic sensitisation over time, especially to grass pollen [29].

Instead of actually measuring endotoxin levels, many studies have used contact with farm animals as a representative measure for increased endotoxin exposure [1, 5-8]. Although, in the present study, animal farmers were indeed exposed to higher airborne endotoxin levels than crop farmers, the highest levels of endotoxin exposure were found among workers who handled plant products, such as grains for animal feed and 

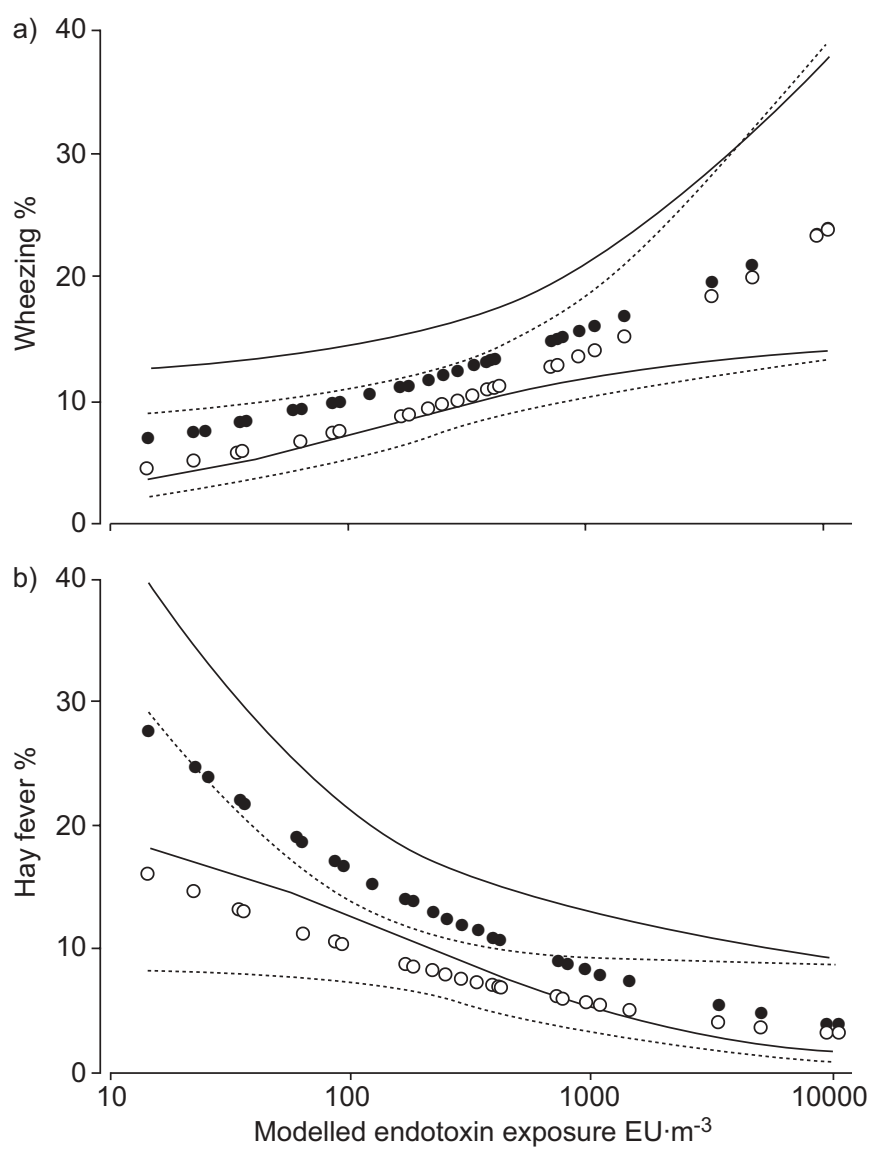

FIGURE 1. Logistic regression plots with pointwise $\pm 1.96 \mathrm{SE}$ bands representing associations between modelled current a) endotoxin exposure and wheezing in the last 12 months, and b) endotoxin exposure and hay fever, in 877 adult agricultural workers stratified by farm childhood. Each symbol represents a group of workers with the same estimated exposure level. EU: endotoxin unit. $\bullet$ : no farm childhood, $n=366$; $O$ : farm childhood, $n=511 ;-: \pm 1.96$ SE bands, no farm childhood; ……...: \pm 1.96 SE bands, farm childhood. Regression coefficient (SE) values: a) — : $0.20(0.09)$; $0: 0.27(0.11)$; b) • : $-0.36(0.10)$; $0:-0.31(0.14)$.

onions in an industrial setting. In previous studies it has been shown that plant products can be heavily contaminated with Gram-negative bacteria and their endotoxins, leading to high exposures among workers processing plant materials like cotton, grain and seeds $[25,26,30]$. The present study showed that the source of endotoxin did not influence risk estimates, whereas health effects depended strongly on measured exposure levels. This clearly demonstrates the importance of quantified endotoxin exposure estimates compared with a crude classification, and potential misclassification, of environments according to the presence of farm animals.

For some of the job titles only a limited number of measurements were available, and it could be argued that this would result in exposure misclassification. However, analyses excluding groups that were measured less than five times (14 job titles, 119 subjects) resulted in very similar ORs (hay fever: OR 0.53 (95\% CI 0.38-0.74); wheeze: 1.35 (1.08-1.69)). In addition, on theoretical grounds, this type of grouping strategy is not very sensitive to the effects of exposure misclassification, and measures of association usually show very little bias [31].
The agricultural sectors that were included in the present study were selected based on the expected heterogeneity of endotoxin exposure levels [26]. Since a monotonous doseresponse relationship was found for all environments, there is no reason to believe that the associations found in the present study cannot be extrapolated to other endotoxin-exposed workers. In previous studies, exposures to agricultural chemicals such as pesticides and disinfectants have also been reported to contribute to wheeze, atopic sensitisation and hay fever [7, 32, 33]. Confounding by chemical exposures in the present study is unlikely, as organic farmers are not allowed to use chemical pesticides or toxic disinfectants, such as chloramine-T and quaternary ammonium compounds. An earlier survey showed only small differences in respiratory health status between conventional and organic farmers, especially after adjusting for potential confounders, including disinfectant use and farm childhood [7]. Thus, the current authors assume that the relationships between endotoxin exposure and health outcomes are representative for conventional farmers as well.

Endotoxin was measured as a marker for microbial exposure. However, most of the workers in the present study were probably exposed to mixed bioaerosols, which may have contained other microbial agents, including $\beta$-1,3-glucan and fungal spores, as well as gases such as ammonia. In farmers, it has been shown that not only endotoxin but also fungal spores and ammonia are positively associated with nonatopic asthma, and inversely with atopic asthma [13]; the individual agents were, however, significantly correlated, which prevented the authors from drawing a definite conclusion regarding the causative agent [13]. In the present study, using inhalable dust as an explanatory variable yielded similar findings to those obtained with endotoxin (data not shown), which is not surprising given the high correlation between both agents $(\mathrm{r}=0.83, \mathrm{p}<0.001)$. Thus, it cannot be excluded that the observed relationships were at least partially due to associated exposures to other agents. However, given its well-known potency as an inducer of inflammatory reactions and activator of immunoregulatory pathways, a major role for endotoxin itself seems highly likely.

Consistent with earlier reports, workers with a farm childhood had a lower prevalence of hay fever, whereas the protective and adverse effects of current exposure to airborne endotoxin were demonstrated in all subjects and no evidence was found of effect modification by farm childhood. By selecting a study population of not only crop and livestock farmers but also workers involved in processing of plant products, a wide range of endotoxin exposure levels was obtained, with relatively balanced numbers of subjects with and without a farm childhood. This enabled investigation of effect modification by farm childhood, which would have been more difficult to achieve in a study consisting only of farmers.

Although the response rate was lower in farmers (61\%) than in other agricultural workers $(90 \%)$, results were similar in the different environments (table 5). It is unlikely that nonresponse bias explains the results, because in that case nonresponse should have had opposite effects in low-exposed farmers (overestimating hay fever and underestimating asthma-like symptoms) and high-exposed farmers (underestimating hay 
TABLE 3 Prevalence of respiratory and allergic symptoms and association with modelled endotoxin exposure in 877 adult agricultural workers, stratified by farm childhood

\begin{tabular}{|c|c|c|c|c|c|c|}
\hline & \multicolumn{2}{|c|}{ All subjects } & \multicolumn{4}{|c|}{ Farm childhood } \\
\hline \multicolumn{7}{|l|}{ Cough symptoms } \\
\hline Daily cough & 8.1 & $1.29(1.03-1.62)$ & 10.2 & $1.10(0.82-1.48)$ & 6.7 & $1.58(1.11-2.25)$ \\
\hline Woken due to cough & 14.1 & $1.36(1.13-1.64)$ & 19.3 & $1.18(0.93-1.50)$ & 10.4 & $1.67(1.25-2.25)$ \\
\hline \multicolumn{7}{|l|}{ SOB and wheezing } \\
\hline Woken due to SOB & 3.3 & $1.47(1.05-2.07)$ & 4.4 & $1.51(0.99-2.32)$ & 2.5 & $1.41(0.82-2.43)$ \\
\hline Wheezing & 11.4 & $1.41(1.16-1.72)$ & 12.8 & $1.33(1.02-1.73)$ & 10.4 & $1.48(1.10-1.99)$ \\
\hline Wheezing with SOB & 7.4 & $1.50(1.18-1.90)$ & 8.5 & $1.42(1.04-1.95)$ & 6.7 & $1.55(1.09-2.21)$ \\
\hline Wheezing without a cold & 6.6 & $1.60(1.25-2.05)$ & 7.9 & $1.70(1.23-2.36)$ & 5.7 & $1.44(0.98-2.12)$ \\
\hline Asthma attack last year & 0.9 & $0.81(0.41-1.63)$ & 1.1 & $0.87(0.36-2.14)$ & 0.8 & $0.79(0.26-2.44)$ \\
\hline Current asthma medication use & 2.3 & $0.71(0.45-1.14)$ & 3.0 & $0.71(0.41-1.24)$ & 1.8 & $0.58(0.25-1.37)$ \\
\hline \multicolumn{7}{|l|}{ Allergy } \\
\hline Any self-reported allergy & 24.9 & $0.82(0.70-0.96)$ & 26.2 & $0.75(0.60-0.93)$ & 23.9 & $0.89(0.70-1.12)$ \\
\hline Hay fever & 10.5 & $0.62(0.49-0.78)$ & 13.7 & $0.59(0.44-0.80)$ & 8.2 & $0.64(0.43-0.95)$ \\
\hline House-dust allergy & 10.4 & $0.86(0.69-1.07)$ & 12.6 & $0.76(0.57-1.00)$ & 8.8 & $1.03(0.74-1.45)$ \\
\hline
\end{tabular}

Data are presented as the odds ratio (OR) for an interquartile range (exp ${ }^{1.45}=$ factor 4.3 ) increase in modelled endotoxin exposure with $95 \%$ confidence interval $(\mathrm{Cl})$, unless otherwise stated. ORs were adjusted for age, smoking habits, sex and (in unstratified analysis) farm childhood. SOB: shortness of breath. ${ }^{\#}: \mathrm{n}=366$; ${ }^{\circ}: \mathrm{n}=511$.

TABLE 4 Prevalence of respiratory symptoms and association with modelled endotoxin exposure in 877 adult agricultural workers, stratified by self-reported allergy

\begin{tabular}{|c|c|c|c|c|c|c|c|}
\hline & \multicolumn{3}{|c|}{ All subjects } & \multicolumn{4}{|c|}{ Allergy } \\
\hline \multicolumn{8}{|l|}{ Cough symptoms } \\
\hline Daily cough & 8.1 & $1.29(1.03-1.62)$ & $1.32(1.05-1.66)$ & 7.3 & $1.39(1.06-1.82)$ & 10.6 & $1.14(0.70-1.84)$ \\
\hline Woken due to cough & 14.1 & $1.36(1.13-1.64)$ & $1.42(1.17-1.71)$ & 12.4 & $1.38(1.10-1.72)$ & 19.4 & $1.48(1.02-2.13)$ \\
\hline \multicolumn{8}{|l|}{ SOB and wheezing } \\
\hline Woken due to SOB & 3.3 & $1.47(1.05-2.07)$ & $1.56(1.10-2.20)$ & 2.4 & $1.38(0.88-2.17)$ & 6.0 & $1.76(1.04-2.98)$ \\
\hline Wheezing & 11.4 & $1.41(1.16-1.72)$ & $1.55(1.26-1.90)$ & 7.6 & $1.51(1.15-2.00)$ & 22.9 & $1.66(1.20-2.31)$ \\
\hline Wheezing with SOB & 7.4 & $1.50(1.18-1.90)$ & $1.65(1.29-2.11)$ & 4.4 & $1.88(1.33-2.67)$ & 16.6 & $1.46(1.03-2.07)$ \\
\hline Wheezing without a cold & 6.6 & $1.60(1.25-2.05)$ & $1.72(1.34-2.21)$ & 4.6 & $1.80(1.28-2.54)$ & 12.8 & $1.70(1.16-2.49)$ \\
\hline Asthma attack last year & 0.9 & $0.81(0.41-1.63)$ & $0.89(0.43-1.82)$ & 0.3 & $1.05(0.30-3.73)$ & 2.8 & $0.83(0.35-1.96)$ \\
\hline Current asthma medication use & 2.3 & $0.71(0.45-1.14)$ & $0.82(0.51-1.32)$ & 0.8 & $0.90(0.41-1.97)$ & 6.9 & $0.65(0.35-1.19)$ \\
\hline
\end{tabular}

Data are presented as the odds ratio (OR) for an interquartile range (exp ${ }^{1.45}=$ factor 4.3 ) increase in modelled endotoxin exposure with $95 \%$ confidence interval, unless otherwise stated. SOB: shortness of breath. ${ }^{\#}: n=659 ;{ }^{\bullet}: n=218 ;^{+}:$ORs were adjusted for age, smoking habits, sex and farm childhood; ${ }^{\varsigma}:$ ORs were adjusted for age, smoking habits, sex, farm childhood and self-reported allergy. 
TABLE 5 Prevalence of wheezing and hay fever and association with high endotoxin exposure within five agricultural sectors

\begin{tabular}{|c|c|c|c|c|c|c|}
\hline & \multirow[t]{2}{*}{ Subjects $n$} & \multirow{2}{*}{$\begin{array}{l}\text { Group median endotoxin } \\
\text { exposure } \mathrm{EU} \cdot \mathrm{m}^{-3}\end{array}$} & \multicolumn{2}{|c|}{ Wheezing } & \multicolumn{2}{|c|}{ Hay fever } \\
\hline & & & $\%$ & OR $(95 \% \mathrm{Cl})$ & $\%$ & OR $(95 \% \mathrm{Cl})$ \\
\hline Flower bulb workers & 126 & 180 & 7.1 & $2.13(0.48-9.38)$ & 8.7 & $0.38(0.09-1.59)$ \\
\hline Animal feed workers & 114 & 320 & 15.8 & $1.78(0.56-5.67)$ & 9.7 & $0.52(0.14-1.95)$ \\
\hline Onion workers & 97 & 4100 & 16.5 & $1.95(0.62-6.15)$ & 6.2 & $0.18(0.02-1.62)$ \\
\hline
\end{tabular}

Data are presented as the odds ratio (OR) for high (above group median) versus low (below group median) endotoxin exposure with 95\% confidence interval (Cl), unless otherwise stated. ORs were adjusted for age, smoking habits, sex and farm childhood. EU: endotoxin unit.

fever and overestimating asthma-like symptoms). Agricultural processing workers were allowed to complete the questionnaire during the working day, which resulted in a high response rate. This health survey was not initiated because of health concerns raised by employees or participating companies; therefore, it does not seem likely that the high response is associated with overestimation of symptoms.

In cross-sectional studies among occupational populations, it is difficult to eliminate healthy worker selection effects. Avoidance of exposure to endotoxin by subjects with any allergic history would have led to an overestimation of the protective effect of endotoxin on hay fever. However, if strong endotoxin-dependent selection effects had taken place, one would expect associations between endotoxin exposure and asthma-like symptoms to be attenuated in the same population, which did not appear to be the case. Moreover, in the subgroup of 429 subjects for whom IgE serology was available, a significant inverse association was observed between endotoxin exposure and allergic sensitisation in subjects who did not report any allergic symptoms; thus, self-selection is unlikely to explain the present results. Nevertheless, a longitudinal study would be necessary to exclude selection effects completely.

In the present study, self-reported data on symptoms was relied upon. Questions on respiratory symptoms, such as current wheezing, were derived from the validated ECRHS questionnaire, and self-reported wheeze and shortness of breath have been shown to be independent predictors for pulmonary obstruction in dust-exposed workers in the Netherlands [34]. In the present study and in other Dutch populations, it has been demonstrated that self-reported allergy and hay fever were strongly associated with atopy, as assessed by skin-prick tests or specific IgE against common allergens $[35,36]$.

In conclusion, the results of the present study demonstrated an inverse exposure-response relationship for hay fever in agricultural workers currently exposed to airborne endotoxin, regardless of childhood farming exposures. At the same time, endotoxin exposure was associated with an increased prevalence of asthma-like symptoms. Although endotoxin might protect workers against allergies, the present study emphasises the need to lower endotoxin exposure levels in the agricultural environment to protect workers against chronic respiratory health effects.

\section{ACKNOWLEDGEMENTS}

The authors would like to thank I. Oosting and M. Visser for technical assistance and L. Portengen for assistance in computing smoothed curves (Institute for Risk Assessment Sciences, Utrecht University, the Netherlands).

\section{REFERENCES}

1 Riedler J, Braun-Fahrländer C, Eder W, et al. Exposure to farming in early life and development of asthma and allergy: a cross-sectional survey. Lancet 2001; 358: 1129-1133.

2 Leynaert B, Neukirch C, Jarvis D, Chinn S, Burney P, Neukirch F. Does living on a farm during childhood protect against asthma, allergic rhinitis, and atopy in adulthood? Am J Respir Crit Care Med 2001; 164: 1829-1834.

3 Portengen L, Sigsgaard T, Omland Ø, Hjort C, Heederik D, Doekes G. Low prevalence of atopy in young Danish farmers and farming students born and raised on a farm. Clin Exp Allergy 2002; 32: 247-253.

4 Kauffmann F, Oryszczyn MP, Maccario J. The protective role of country living on skin prick tests, immunoglobulin $\mathrm{E}$ and asthma in adults from the Epidemiological study on the Genetics and Environment of Asthma, bronchial hyper-responsiveness and atopy. Clin Exp Allergy 2002; 32: 379-386.

5 Radon K, Schulze A, Nowak D. Inverse association between farm animal contact and respiratory allergies in adulthood: protection, underreporting or selection? Allergy 2006; 61: 443-446.

6 Dimich-Ward H, Chow Y, Chung J, Trask C. Contact with livestock - 3a protective effect against allergies and asthma? Clin Exp Allergy 2006; 36: 1122-1129.

7 Smit LA, Zuurbier M, Doekes G, Wouters IM, Heederik D, Douwes J. Hay fever and asthma symptoms in conventional and organic farmers in The Netherlands. Occup Environ Med 2007; 64: 101-107.

8 Koskela HO, Happonen KK, Remes ST, Pekkanen J. Effect of farming environment on sensitisation to allergens continues after childhood. Occup Environ Med 2005; 62: $607-611$. 
9 Gereda JE, Leung DY, Thatayatikom A, et al. Relation between house-dust endotoxin exposure, type $1 \mathrm{~T}$-cell development, and allergen sensitisation in infants at high risk of asthma. Lancet 2000; 355: 1680-1683.

10 Braun-Fahrländer C, Riedler J, Herz U, et al. Environmental exposure to endotoxin and its relation to asthma in school-age children. N Engl J Med 2002; 347: 869-877.

11 Douwes J, van Strien R, Doekes G, et al. Does early indoor microbial exposure reduce the risk of asthma? The Prevention and Incidence of Asthma and Mite Allergy birth cohort study. I Allergy Clin Immunol 2006; 117: 1067-1073.

12 Gehring U, Bischof W, Schlenvoigt G, et al. Exposure to house dust endotoxin and allergic sensitization in adults. Allergy 2004; 59: 946-952.

13 Eduard W, Douwes J, Omenaas E, Heederik D. Do farming exposures cause or prevent asthma? Results from a study of adult Norwegian farmers. Thorax 2004; 59: 381-386.

14 Portengen L, Preller L, Tielen M, Doekes G, Heederik D. Endotoxin exposure and atopic sensitization in adult pig farmers. J Allergy Clin Immunol 2005; 115: 797-802.

15 Michel O. Role of house-dust endotoxin exposure in aetiology of allergy and asthma. Mediators Inflamm 2001; 10: 301-304.

16 Liu AH. Endotoxin exposure in allergy and asthma: reconciling a paradox. J Allergy Clin Immunol 2002; 109: 379-392.

17 Thorne PS, Kulhánková K, Yin M, Cohn R, Arbes SJ Jr, Zeldin DC. Endotoxin exposure is a risk factor for asthma: the national survey of endotoxin in United States housing. Am J Respir Crit Care Med 2005; 172: 1371-1377.

18 Vogelzang PF, van der Gulden JW, Folgering $\mathrm{H}$, et al. Endotoxin exposure as a major determinant of lung function decline in pig farmers. Am J Respir Crit Care Med 1998; 157: 15-18.

19 Castellan RM, Olenchock SA, Kinsley KB, Hankinson JL. Inhaled endotoxin and decreased spirometric values. An exposure-response relation for cotton dust. $N$ Engl J Med 1987; 317: 605-610.

20 Von Essen S, Fryzek J, Nowakowski B, Wampler M. Respiratory symptoms and farming practices in farmers associated with an acute febrile illness after organic dust exposure. Chest 1999; 116: 1452-1458.

21 Burney PG, Luczynska C, Chinn S, Jarvis D. The European Community Respiratory Health Survey. Eur Respir J 1994; 7: 954-960.

22 Rijcken B, Kerkhof M, de Graaf A, Boezen HM, Droste JHJ, Kremer AM. [European Respiratory Health Survey The Netherlands.] Groningen, Stichting drukkerij Regenboog, 1996..

23 Douwes J, Versloot P, Hollander A, Heederik D, Doekes G. Influence of various dust sampling and extraction methods on the measurement of airborne endotoxin. Appl Environ Microbiol 1995; 61: 1763-1769.

24 Rappaport SM, Lyles RH, Kupper LL. An exposureassessments strategy accounting for within- and betweenworker sources of variability. Ann Occup Hyg 1995; 39: 469-495.

25 Smit LA, Wouters IM, Hobo MM, Eduard W, Doekes G, Heederik D. Agricultural seed dust as a potential cause of organic dust toxic syndrome. Occup Environ Med 2006; 63: 59-67.

26 Spaan S, Wouters IM, Oosting I, Doekes G, Heederik D. Exposure to inhalable dust and endotoxins in agricultural industries. J Environ Monit 2006; 8: 63-72.

27 Doekes G, Douwes J, Wouters I, de Wind S, Houba R, Hollander A. Enzyme immunoassays for total and allergen specific IgE in population studies. Occup Environ Med 1996; 53: 63-70.

28 Herrick CA, Bottomly K. To respond or not to respond: T cells in allergic asthma. Nat Rev Immunol 2003; 3: 405-412.

29 Prior C, Falk M, Frank A. Longitudinal changes of sensitization to farming-related antigens among young farmers. Respiration 2001; 68: 46-50.

30 Olenchock SA, Christiani DC, Mull JC, Ye TT, Lu PL. Endotoxins in baled cottons and airborne dusts in textile mills in the People's Republic of China. Appl Environ Microbiol 1983; 46: 817-820.

31 Armstrong BG. Effect of measurement error on epidemiological studies of environmental and occupational exposures. Occup Environ Med 1998; 55: 651-656.

32 Hoppin JA, Umbach DM, London SJ, Alavanja MC, Sandler DP. Chemical predictors of wheeze among farmer pesticide applicators in the Agricultural Health Study. Am J Respir Crit Care Med 2002; 165: 683-689.

33 Preller L, Doekes G, Heederik D, Vermeulen R, Vogelzang PF, Boleij JS. Disinfectant use as a risk factor for atopic sensitisation and symptoms consistent with asthma: an epidemiological study. Eur Respir J 1996; 9: 1407-1413.

34 Meijer E, Grobbee DE, Heederik DJ. Health surveillance for occupational chronic obstructive pulmonary disease. J Occup Environ Med 2001; 43: 444-450.

35 Crobach MJ, Hermans J, Kaptein AA, Ridderikhoff J, Petri H, Mulder JD. The diagnosis of allergic rhinitis: how to combine the medical history with the results of radioallergosorbent tests and skin prick tests. Scand J Prim Health Care 1998; 16: 30-36.

36 Droste JH, Kerhof M, de Monchy JG, Schouten JP, Rijcken B. Association of skin test reactivity, specific IgE, total IgE, and eosinophils with nasal symptoms in a community-based population study. The Dutch ECRHS Group. J Allergy Clin Immunol 1996; 97: 922-932. 